tributyrin is rapidly hydrolysed, is not emulsified and the butyric acid formed is dispersed about equally between the oil and water phase. P. Desnuelle (Marseilles) gave an account of the extensive study by his group of the products of lipolysis under various conditions. The rate of hydrolysis of different glycerides varies, and the reasons for this were discussed. B. Borgström (Lund) claimed that there is considerable re-formation of glycerides and transesterification, so that all the fatty acids in the glyceride may have been detached at some time in the course of the reaction. He agreed, however, that intestinal absorption of glycerides could occur without complete hydrolysis. After discussion it was generally agreed that the basic concept of the Pflüger-Verzar hypothesis that complete hydrolysis of glycerides is an essential step in fat absorption is not correct.

Consideration of the cellular phase of fat absorption was begun by H. G. Sammons (Birmingham), who discussed the passage of lipids through the outer border of the intestinal cell. $\mathrm{He}$ presented the evidence for considering that the outer border of the intestinal cell has a canalicular structure and described experiments on the absorption of long-chain and short-chain glycerides, paraffin, castor oil and water-insoluble esters, all of which illustrated in various ways the close relationship between fine emulsification in the intestinal lumen and absorption of the water-insoluble glyceride fraction. Considerable discussion followed, both on the structure of the outer border of the intestinal cell and on particulate absorption. P. Favarger (Geneva) presented a paper on the relationships between the absorption of glycerides and sterols, which, he felt, introduce the necessity for some transport mechanism more specific than simple oil-solubility. It might be that particulate absorption only carries lipids to the bottom of the fine canals and at this point some selective carrier mechanism for sterols might come into action. There do not appear to be sufficient data available at present to resolve these problems.

Consideration of the distributive phase of absorption was introduced by A. C. Frazer (Birmingham), who described the almost quantitative recovery of long-chain glycerides from the chyle. This lipid is finely emulsified and gives rise to the classical alimentary systemic hyperlipæmia. In human subjects with no pancreatic lipase as shown by intestinal intubation, no intraluminar emulsification and no alimentary hyperlipæmia occur. If a finely dispersed oil-in-water emulsion containing particles less than $0.5 \mu$ in diameter is injected intraduodenally in such patients, a normal systemic hyperlipæmia occurs.

Certain lipids, however, are absorbed, but cannot be quantitatively recovered from the chyle. This has been observed in the case of short-chain fats and paraffins. These substances must either be meta. bolized in the intestinal cells or transported into the body by the alternative portal route. In the case of the shorter-chain fatty acids, transport in the portal vein has already been demonstrated, using decanoic acid labelled with carbon-14. The possibility of metabolic modification in the intestinal cell is an important consideration in the study of selective absorption. J. Fernandes, in collaboration with H. A. Weijers and J. H. Van de Kamer (Centraal Instituut voor Voedingsonderzoek, Utrecht), described studies carried out on a patient with a chylothorax. Long. chain fats were readily recovered from the chyle but short-chain fats were not. H. J. Thomasson
(Unilever Research Laboratories, Zwijndrecht) described a new method for the biological assay of essential fatty acids.

The final session was opened by S. J. Folley (Reading), who described his classical work on the synthesis of lipids in mammary gland slices, with special reference to the influence of endocrine factors. $J$. Peeters (Ghent) continued with an account of his studies using the perfused udder. G. Popják (National Institute for Medical Research, London) presented the evidence for considering that fatty acids and cholesterol can be built up from 2-carbon fragments, and he described studies showing the synthesis of fatty acids from glucose labelled with carbon-14. R. Ruyssen (Ghent) described the incorporation of carbon-14 into fatty acids, and $K$. Bloch (Chicago) presented the evidence for the formation of cholesterol from squalene, and discussed the probable way in which this may occur. S. Bergström (Lund) gave an account of the methods he has developed for the detailed study of individual bile acids. K. Bernhard (Basle) described synthetic lipids containing triple bonds. This concluded the last scientific session.

The members of the colloquium decided to arrange future meetings from time to time, to discuss biochemical problems involving lipids. The Royal Flemish Academy of Sciences was thanked for its generous support, and the colloquium was formally closed by the president of the Academy. The full proceedings of the colloquium will be published in due course.

\section{ANIMAL AND VEGETABLE RESOURCES OF GREAT BRITAIN}

A BOUT five years ago suggestions were made to A the Lord President's Office, in papers submitted by Dr. F. N. Woodward and Mr. A. N. Duckham, that more attention should be given in Britain to increasing the efficiency of the production and utilization of agricultural crops and other biological materials. Emphasis was placed upon possible uses for waste products, and it was pointed out that in the United States four regional laboratories had already been established for this purpose under the Bureau of Agricultural and Industrial Chemistry. Eventually, a team of three experts was chosen, made up of Dr. Woodward, Dr. A. B. Stewart and the late Mr. John Maxton, for the purpose of surveying all branches of industry concerned with biological, as distinct from mineral, products. The team proceeded to approach about two hundred individuals or organizations in the fields to be covered, including forty-two government departments, thirty-six research organizations, sixty-one industrial firms, twenty producers and manufacturers' organizations and twelve university departments. Its report, "A Survey of Agricultural, Forestry and Fishery Products in the United Kingdom and their Utilization", has recently been published under the auspices of the Development Commission*.

More than formal tribute is due to the memory of Mr. John Maxton, who was director of the Institute of Agrarian Affairs in the University of Oxford, for his editorial skill in condensing vast masses of important information into a report which is concise,

* Development Commission. A Survey of Agricultural, Forestry and vi 141. (London: H.M.S.O., 1953.) 78. 6d. net. 
well arranged and pleasant to read. The subjects covered actually exceed the scope of the title in including imported agricultural crops which are processed in Britain, such as oil-bearing seeds, and also industrial biological products, such as malt, alcohol and antibiotics. Foodstuffs certainly predominate among the materials investigated, but attention is also given to non-edible products such as timber, leather, wool, cotton, paper and glue.

Agricultural crops. In Britain farmers grow only about one-third of the nation's wheat requirements, and nearly all the maize is imported. Almost all the barley and oats, however, are home grown. About half the barley is made into malt, and is used mainly for brewing and distilling; most of the rest is given to farm animals, which also receive nearly 80 per cent of the oats. The small quantity of home-grown rye is used for human consumption. The economical use of straw has attracted attention, and by predigestion with alkali its digestibility by animals has been increased. In the sugar beet industry the residual pulp left after the removal of the sugar has proved valuable as fodder, but an economical use for the foliage has still to be found. Pomace, left after pressing apples for making eider, is used both as fodder and as a source of pectin for the jam industry. Interesting regional differences are seen in the production of different vegetable crops in various parts of the country. Thus Ulster specializes in potatoes, Lincolnshire in peas and beans, and East Anglia in sugar beet. Peat is classified, perhaps rather strangely, as an agricultural crop ; it contains about 12 per cent of wax which might be used for the manufacture of polishes and in electric cables. The imported crops which are processed in Britain include oil-bearing seeds, coffee, tea, cocoa, cotton, jute, hemp and tobacco.

Animal products. Milk is such an excellent food that it is wasteful, except when the production exceeds the demand, to use it other than in liquid form. It is satisfactory, therefore, that only 10 per cent of the output in Britain is used for making butter, cheese, dried milk and other products. In the meat industry little seems to be wasted, except quantities of blood which exceed the capacity of the processing plants. Whole dried blood is used as a fertilizer, and the separated albumin in making plywood and paint. Collections of organs and glands for the extraction of hormones and other medical products are now made on 85 per cent of the animals killed in government slaughter-houses. A valuable source of leather is lost because few pigs are flayed, because bacon and pork are best marketed with the skin intact. Wool fat is a rich source of various waxy alcohols and also of cholesterol, which is a valuable starting material for the synthesis of certain hormones and vitamin $\mathrm{D}_{3}$. In the Bradford area no less than 8,500 tons of wool wax are recovered annually from the sewage; most of the wax is used on the railways as axle grease.

Biological products. The brewing industry, with all its ramifications, is based essentially on the culture of micro-organisms. It is estimated that 130,000 tons of carbon dioxide are given off annually in the course of brewing. The gas has several important industrial applications, but the supply far exceeds the demand. A more modern application of microbiology has been the production of antibiotics such as penicillin and streptomycin. The 'felt' formed by the micro-organisms is a rich source of vitamins of the B group. Starch is produced in Britain to the extent of 46,000 tons from maize, with only 2,100 tons from rice and 3,850 tons from wheat.

Timber. In Britain there is only 0.07 of an acre of forest per person as compared with $6 \cdot 47$ acres in Norway and 0.85 acre in Europe as a whole. The constant need to import timber, and the chronic scarcity of supplies, are therefore readily understandable. Steps are being taken to rebuild the stock of standing timber after the inroads made necessary by the Second World War. Although one cannot hope to satisfy current requirements, reserves may at least be accumulated against a future emergency. Most of the timber is located in Scotland. Attention is also being given to the efficient use of wood waste. Small pieces of wood and sawdust may be used to make hard-board, paper or briquettes for fire lighting. Vanillin may be manufactured from the sulphite liquor obtained in the manufacture of paper from wood. The liquor may also be fermented to give alcohol, yeast or other products.

Research and development. The report includes a useful list of the research institutions concerned in the production or efficient utilization of the materials which come within its scope. The absence or sparsity of the analytical data on many important products is stressed, and the collection of more adequate information is strongly urged. Another pressing need is the provision of more adequate facilities for investigating processes for industrial application on the 'pilot plant' scale. Only a few laboratories have any plant at all, and it is usually old-fashioned or even unserviceable. Practically no chemical engineers, moreover, are employed by the Department of Scientific and Industrial Research, and none by the Ministry of Agriculture and Fisheries or by the Agricultural Research Council.

The authors are to be congratulated for enabling research workers employed by these organizations, and others, to learn more of what is going on outside their own orbits of activity. The prosperity of Great Britain may largely depend on how far this widening and quickening of interest can be sustained and extended. THOMAS MOORE.

\section{RESEARCH AND DEVELOPMENT AT NON-PROFIT INSTITUTIONS IN THE UNITED STATES*}

A STUDY of the funds administered by United A States Federal agencies for research and development at non-profit institutions during 195051 and 1951-52, which has recently been completed by the National Science Foundation, indicates the extent to which the Federal Government now sponsors research and development at such institutions, rather than conducting the work in its own laboratories. While in 1940 sponsored research and development accounted for less than 10 per cent of all government expenditure for this purpose, in 1952 it accounted for 75 per cent. According to the study, Federal agencies administered $\mathbf{3 3 8}$ million dollars for scientific research and development at non-profit institutions during 1951-52, compared with 294 million dollars

* The National Science Foundation. Federal Funds for Science. 1 ; Federal Funds for Scientiflc Researeh and Development at Non-profit Institutions $1950-1951$ and $1951-1952 .{ }_{0}$ Pp. vi +48 . 